\title{
Fluid Dynamic Aspects of Room Fires
}

\author{
E. E. ZUKOSKI
}

Karman Laboratory of Fluid Mechanics and Jet Propulsion

California Institute of Technology

Pasadena, California 91125, USA

\section{ABSTRACT}

Several fluid dynamic processes which play important roles in the development of accidental fires in structures are discussed. They include a review of information concerning the characteristic flow regimes of fire plumes and the properties of the flow in these regimes, and a brief review of flow through openings and in ceiling jets. Factors which lead to the development of thermal stratification in ceiling layers are also discussed.

\section{INTRODUCTION}

A review is presented in this paper concerning several fluid dynamio processes which have a strong influence on the development of a fire within a compartment. We have selected only a few to discuss here in depth and more inclusive and detailed discussions of all or selected examples of these processes are given in Rocket (1975), Emmons (1978), Steckler et al (1982), Quintierre (1984) and Zukoski (1985).

To introduce the subject, consider the sketches of Figure 1 which outline the growth of a fire within a two room structure. In the initial stages of a fire within an enclosure, the plume of hot gas produced by the fire rises due to buoyancy forces and impinges on the celing to form a thin layer of hot gas. This layer spreads out across the celling and then grows in depth to form a more or less well defined hot gas layer, called here the ceiling layer. The plume entrains gas from the air in the room and acts as a primary source of material for the celling layer.

In the first moment of the fire, the ceiling layer will have negligible thickness and gas in the fire plume can only entrain air at the ambient temperature as it rises toward the ceiling. The average temperature of the gas at the level of the ceiling will be fixed by the rate of heat addition from the fire and the rate of entrainment of cool, unvitiated air from the room. When the fire is small, most of the material in the plume will be air and only a small fraction will be products of combustion.

As the thickness of the ceiling layer grows due to the addition of plume material, the plume still penetrates the layer and it 

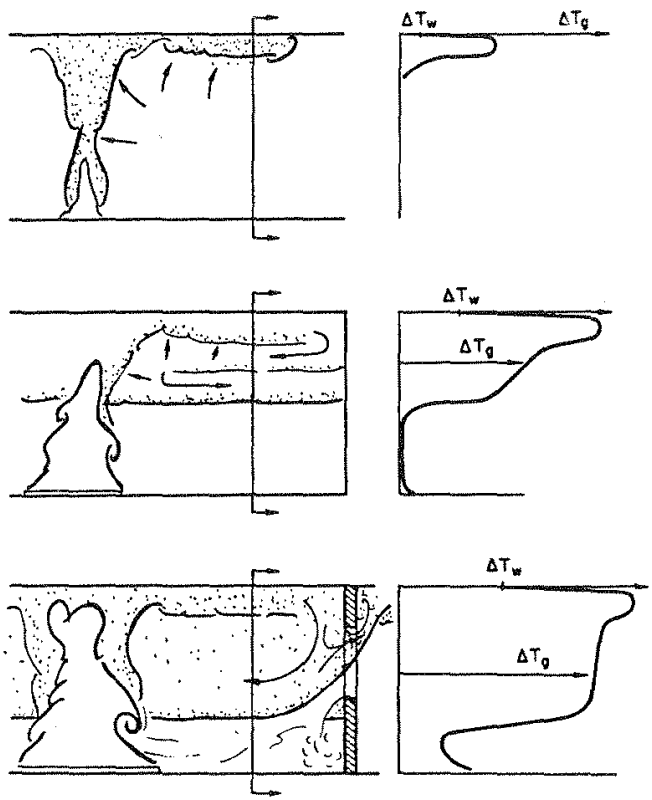

FIGURE 1. Development of the cefling layer.

impinges on the ceiling to form a relatively hot ceiling jet within the ceiling layer. Consequently, it is useful to think of the gas from the fire plume as being added at the top of the ceiling layer. The gas in the plume will also begin to entrain fluid from the hot Bas in the ceiling layer. Because the relative importance of the entrainment from the hot layer grows as the layer thickness grows, the temperature of the gas arriving at the ceiling will increase as the layer thickness grows and this temperature increase will become still larger if the heat release rate of the fire increases with time.

Thus, the temperature of the gas delivered to the ceiling will be higher than that of the ceiling layer even when the layer itself is well mixed and adiabatic. In addition, convective and later radiative heat transfer to the walls will reduce substantially the temperature of the ceiling layer gas below the adiabatic value and hence will further increase this difference.

Because of these processes, we expect that there may be a considerable temperature variation across the height of the layer. The degree of stratification in the ceiling layer will depend in detail on the flow within the layer, changes in the heat release rate of fires, the enthalpy fluxes resulting from the flow of gas into and out of the layer at openings, and heat loss to the walls. Several of these processes will be discussed in a later part of this paper.

Later in the history of this fire, gas will flow out of the doorway and will form a ceiling layer in the adjacent space. The 
plume formed at the doorway will have the same history of increasing temperature as that in the room of origin and many of the features described above will be repeated.

The model. which is most widely used to describe the propagation of fire and the motion of smoke through buildings described above is the two-layer model. The basic assumption made in this model is that the gas in any space can be usefully separated into two horizontal and homogeneous layers: a hot ceiling layer and a cooler floor

layer. In developing equations to describe the growth of these layers and changes in their properties with time, the assumption is made that only a single set of parameters such as temperature and species concentrations are required to describe each layer.

One of the great simplifications resulting from the use of this type of model is that the details of the flow within the layers can be ignored. However, it is evident from the above discussion that at least a rudimentary description of flow within the layer is required to allow a description of convective and radiative heat transfer from the gas to the surfaces of the room.

In addition, recent experiments suggest that large temperature gradients can exist in ceiling layers produced in large scale fires and laboratory test equipment. These experiments suggest that for certain conditions the formation of homogeneous layers in a room may be a very poor assumption, and they have led us to consider and to discuss here the factors which might cause the development of poorly mixed layers.

The purpose of this paper is to review briefly our understanding of several fluid dynamic processes which influence the progress of fires of the type described here. These are the fire plume, flows through openings and ceiling jets. We then examine some of the factors to determine the degree of stratification which can exist in the ceiling layer.

\section{BUOYANT FIRE PLUMES}

The diffusion flame and accompanying buoyant plume which are present in a room fire act as the engine which entrains fresh air from the lower layer and pumps products into the upper layer. The entrainment characteristics of the fire, the region of heat release made visible by combustion processes, and the adiabatic plume rising above it $f i x$ the temperature and mass transfer rate of hot gas into the upper layer. The flame height becomes an important scaling parameter beoause the entrainment oharacteristics of the flame ano plume are different, and because the radiant flux to the fuel bed which controls the growth of the fire depends on the flame geometry. Finally, the height of the flame enters into the behavior of the adiabatic plume rising above it because the heat addition region or flame acts as the source for the plume.

The flow field produced by a large diffusion flame in the region in which rapid heat release occurs is not yet well understood. In contrast, the flow field of an isolated, adiabatic, and axisymmetric buoyant plume has been one of most frequently studied flows which occur in room fires and, over the past fifteen years, we have obtained the information required to produce good 
predictions for the properties of this flow which are required in fire models.

However, our understanding of the entrainment process in this flow is no better now than that used in the integral models of Morton et al (1955). For example, the local entrainment rate of ambient fluid into a buoyant plume is almost twice that in a momentum dominated jet. Despite the fact that we can describe either of these flows in terms of simple algebraic formulae, we do not yet understand this difference in entrainment rates.

Furthermore, these descriptions apply in the region far from the source of the plume, whereas in fire problems we are most often interested in the region near the source where the initial conditions are important.

\section{Flow Regimes and Transition Criteria}

Before proceeding, it is convenient to discuss the flow regimes of interest to us. In many flows arising in acoidental fires, we must deal with diffusion flames which have source diameters of one to several meters. In these flames, the gaseous fuel is often generated by a pyrolysis process which produces maximum mass fluxes of 10 to $30 \mathrm{grams} / \mathrm{s} / \mathrm{m}^{2}$ with maximum velocities at the fuel surface of 1 to $2 \mathrm{~cm} / \mathrm{sec}$. In general, we characterize the flames and the plumes which rise above these fuel sources as being turbulent and buoyancy controlled flows.

Problems arise when we attempt to define criteria which will allow us to determine whether or not scaling laws derived from laboratory experiments will follow the scaling laws for full scale turbulent and buoyancy controlled flows. The transition between laminar and turbulent flows and the operational significance of the difference between unsteady laminar flows, which contain highly wrinkled laminar flames, and turbulent flows is often obscure and a body of data does not yet exist from which a convincing set of criteria can be developed to define the laminar to turbulent transition in these flames.

It is convenient to introduce two parameters which will be used here to describe the initial conditions in jets and plumes. The first is Q*, a dimensionless heat release parameter which has been found useful, Zukoski (1975), in describing large diffusion flames and plumes, and is discussed below in the Flame Height section. It is defined as,

$Q^{*}=\dot{Q} /\left(\rho_{\infty} C p_{\infty} T_{\infty} \sqrt{g D} D^{2}\right)$

Here $\dot{Q}$ is the heat release rate of the fire and $\rho_{\infty}, C_{\infty}$, and $T_{\infty}$ are the density, specific heat at constant pressure and temperature of the ambient fluid, $g$ is the acceleration of gravity and $D$ is the burner diameter.

The second parameter is a Froude number given by Fro $=W^{2} / g D$ when the source has a constant density $\rho_{0}$ and velocity Wo. The two parameters are related by

$Q^{*}=\left[0.8\left(h_{f} / \mathrm{Cp}_{\infty} \mathrm{T}_{\infty}\right)\left(\rho_{0} / \rho_{\infty}\right)\right] \sqrt{\mathrm{Fro}}$ 
Here, hf is the heating value and the density of the fuel at the source. The product of density ratio and heating value differ by about a factor of ten, comparing hydrogen and propane, for typical fuels. For hydrocarbon fuels, the differences are much smaller.

The transition to turbulence in plumes has been described by Railston ( 1954 ), who proposed a transition criterion based on information obtained for transition in adiabatic plumes above a heat source, which can be put in the form,

$Z t / D=2000 /\left[(Q *)^{1 / 3}\right][\sqrt{G D} D / \nu]$

Application of this result to fire problems indicates that most plumes of interest to us will be turbulent.

Becker and Liang (1978) give a review of ideas concerning transition in flames. They propose that a Reynolds number, based on their estimate of the properties of the flow at the top of the flame, be used to predict the transition to turbulence. For the low $Q^{*}$ range of primary interest here, this parameter is essentially the square root of a Grasshof number based on the flame length which can be put in the form,

Re $=0.14 \quad \mathrm{Zf} \sqrt{[\mathrm{g} \mathrm{Zf]}} / \nu_{\infty}$

For the range, $1<\mathrm{zf} / \mathrm{D}<5$, they suggest 2500 as the transition Reynolds number when the kinematic viscosity, $\nu_{\infty}$, is evaluated for air at standard conditions. This oriteria reduces to the statement that the flame length should be greater than $0.2 \mathrm{~m}$ to insure that the flow will be turbulent. This choice appears to be entirely based on the data of BIinov and Khudiakov (1957) and we believe that it deserved further study. The applicability of this result to flows with larger or smaller ratios $\mathrm{Zf} / \mathrm{D}$ is untested.

A second criterion concerns the relative importance of buoyancy forces with respect to the initial momentum flux in the flow. At the source of an adiabatic jet or flame plume which has some initial momentum, the momentum with which the fuel is injected may be so large that buoyancy forces are unimportant. In this region, the momentum flux will be close to the value at the souroe, and flow characteristics, such as entrainment rates, will be those of a momentum dominated jet with no influence of buoyancy. However, buoyancy forces act over the entire height of the flame and cause the momentum flux in the flow to increase with height. Therefore, at some point farther away from the origin, the momentum starts to increase rapidly above the initial value, where the flow becomes buoyant controlled and the flow characteristics will be those for a buoyant plume with no initial momentum flux but with some offset of origin.

For an adiabatic jet, this transition occurs at an elevation zt which can be expressed as

$z t / D=($ Constant $)\left(W 0^{2} /\left(B^{+} D\right)\right)^{1 / 2}$

Here, $g^{\prime}$ is the reduced acceleration of gravity, $g\left(\rho_{\infty}-\rho_{0}\right) / \rho_{0}, \rho_{\infty}$ is the ambient density, and $\rho_{0}$ is the initial density in the jet. 
Becker and Yamazaki (1980) and Becker and Liang (1980) have also observed this transition in their measurements of the momentum and mass fluxes in turbulent jet diffusion flames. They found that the region over which the initial momentum is important is related to a Froude number for the source Fro and a density ratio, $\left(\rho_{0} / \rho_{\infty}\right)$. Here $\rho_{0}$ is the density in the jet at the source and $\rho_{\infty}$ is the ambient gas density. A similar model, see zukoski (1985), suggests that the density dependence should involve the mean gas density in the flame. Using either of these models, we expect that the transition will occur within a flame at an elevation $z t$ above the source given roughly by:

$\mathrm{Zt} / \mathrm{D}=($ Constant $)\left(\rho_{0} / \rho_{\infty}\right)^{2 / 3}\left[\mathrm{Wo} /(\mathrm{gD}]^{1 / 3}\right.$

The transition is a broad one and a value for the constant lies between 1 and 5 depending on the experimental criteria used to define transition.

Transition of a different type arises when we examine the properties of buoyancy controlled flames. The dependence of the flame height on heat release rate, the initial momentum and sourcediameter change markedly when the ratio of flame height to sourcediameter is between 1 and 3. Thus, these data suggest that two regimes exist, one for tali flames and a second when the ratio of flame height to source-diameter is less than one.

Finally, based on measurements of entrajnment rates and of temperature and velocity, we must distinguish at least two regions within a buoyant diffusion flame in which the the dependence of these properties on position and source-diameter are quite different. In flames which are more than three source-diameters high, this transition occurs at about $60 \%$ of the average flame height for the entrainment data of cetegen et al (1984) and the velooity and temperature data of Mocaffrey (1979). This transition is associated with the intermittency of the flame which begins to fall rapidly at these elevations.

The transitions and regimes described above are illustrated by the sketch of Figure 2 in which the dependence of flame height on the two flow parameters described above is shown for a wide range of values. To have a concrete example in mind, consider a flame produced by a constant fuel flow rate from a circular burner and examine the changes in the flame height as the diameter of the burner is increased from a small diameter to a very large one. When the diameter of the jet is very small, the Froude number for the source, Ero, is very much larger than one and the entire flame is momentum dominated. The flame length to diameter ratio $\mathrm{Zf} / \mathrm{D}$, see regime $V$ in Figure 2 , is roughly independent of the Froude number but has been shown to depend on the stolchiometric fuel-air ratio. For this reason, Q* is not an appropriate scaling parameter in this regime. The flame is a single well defined jet-like structure with considerable intermittency at the tip and a steady cone-like geometry at the base.

The broken line in Regime IV marks roughly the transition from momentum to buoyancy controlled flows suggested by the criteria given above. Presumably this transition line extends into the adiabatic plume region above the flame although no measurements are available to verify this conjecture. 


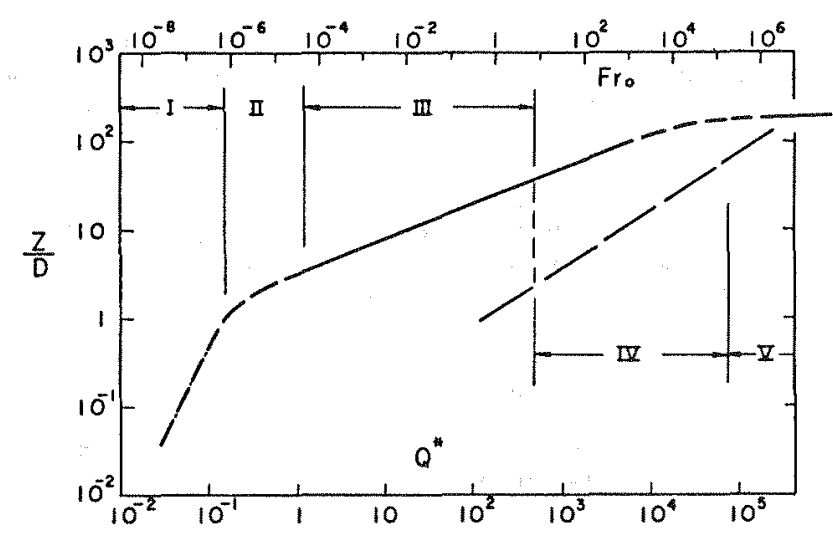

FIGURE 2. Schematic diagram of flame length versus fuel flow rate parameters.

When the diameter of the jet is increased, the Froude number decreases and the flames cross this transition line. Then, starting at the top of the flame, the influence of buoyancy will become more important and eventually the whole flow will be buoyancy controlled. In this regime, regime III, $Q^{*}$ appears to be an appropriate parameter to describe the flow. Because the slope of the curve is about $2 / 5$, the flame length is independent of the source diameter and depends primarily on the heat release rate. The flame is still. a well defined column but, as $Q^{*}$ decreases toward one, a regular pulsation at the base of the flame grows in amplitude and the length of the intermittent flame region at the tip of the flame grows as a fraction of flame length. See, for example, Cetegen et al (1984).

For a still larger diameter souroe, a second transition, see regime II in Figure 2 , is reached for values of $Q$ between 1.0 and 0.10 . In this transition region, the flame breaks up into a number of independent flamelets as $Q^{*}$ decreases and the flame height depends on the diameter and heat release rate.

Finally, there is evidence that a third regime exists for $1.0>(\mathrm{Zf} / \mathrm{D})$, or $\mathrm{Q}^{*}<0.1$. In this regime, called regime $I$ on Figure 2, the height of the flamelets appears to become roughly independent of the sourcemdiameter and to depend only on the local heat release rate per unit area, i.e., on the fuel flow per unit area. This type of behavior seems reasonable in the limit of very large diameter sources if the transport of oxygen into gas above the center of the fuel bed is also independent of the diameter of the bed. Experiments carried out with large laboratory fires, see the discussion in Wood et al (1971), and with very large scale fires, such as the the Flambeau Tests suggests that this is a reasonable assumption. For further discussion, see Zsak and Zukoski (1985).

However, the transition between the last two regimes may not be so simply distinguished as that between the first two and the transition between turbulent and laminar flows may be important 
here. For example, in laboratory tests with sourcemiameters of the order of a meter or less, this regime is only accessable when flame heights are in the 10 to $20 \mathrm{~cm}$ height range. These values lie close to the 0.2 meter limit suggested above for the transition to laminar flow and thus results of experiments at this scale may not be

applicable to large scale fires. Finally, there is no good evidence yet to support the idea that the Q parameter is the appropriate one in this regime. However, the dependence of the flame length on the heat release rate per unit area seems well established.

\section{Characteristics of Isolated Fire Plumes}

In this section we will describe some of the characteristics of flames formed above simple fuel beds such as a pool of liquid fuel or a bed of glass beads with fuel supplied by the infection of natural gas. The initial diameter of these fires is well defined as the diameter of the pool or bed and the flame lies above a well defined level fixed at the top of the bed or pool. Defining similar geometric characteristics for flames formed above more complex fire sources, such as a burning crib with a large height to width ratio, is a more difficult task which has not yet been addressed satisfactorily. For example, when the crib height and the flame height measured from the floor are comparable, then the definition of the flame height becomes difficult and we should expect the correlations given below to fail.

In the following paragraphs of this section, we will restrict our discussion to axisymmetric diffusion flames and plumes. Information is avaliable for adiabatic plumes rising above a line source, but little is available for flames above a line source or other geometries.

Unsteady flow In flames. One of the interesting characteristios of many diffusion flames with a height to sourcediameter ratio greater than 1.0 is the unsteady flow they produce. Immediately above the bed which fixes the origin of the fire, the flame surface pinches in periodicaliy toward the axis of symmetry and produces a distinct structure in the flame which has the appearance of a large irregular donut-shaped vortex ring. This structure rises slowly above the source and defines the top of the flame when the fuel it contains burns out. In a flame with a large height to diameter ratio, several of these structures are present at any iven time and for flames with a height to diameter ratio of two to three diameters, only one structure is visible at a time. For flames with a height to diameter ratio less than one, the process can not be seen in the visible flame, but does appear in shadowgraph images of the rising plume of hot products.

This process has been the subject of numerous investigations, e.g. Thomas et al (1965) and recent reviews are given in zukoski et al (1981), Beyler (1984) and cetegen et al (1984). The dominant frequency appears to scale as $\sqrt{g / D^{\prime}}$ for a wide range of diameters and fuels. The fluctuations are most marked when $Z f / D$ is between one and three, and the amplitude of the fluctuations decreases markedly as zf increases from 3 to 20 source-diameters where the initial momentum becomes important. Due to the discrete nature of these structures, the instantaneous height of the visible flame is very unsteady and it fluctuates over a distance equal to $80 \%$ of the 
In these ranges of $Z f / D$, photographic measurements of the geometry of the flame taken by cetegen et al (1984) show the flame is always present at elevations in the lower part of the flame and hence that the intermittency is one there. However, above some elevation, the intermittency decreases almost linearly to zero as the elevation is increased. The "average flame height" is defined in this paper as the 50\% intermittency point in contrast to "eye averaged values" which typically record the top of the flame where the intermittency approaches zero. Because the fluctuations in height of the top of the visible flame are so large, the averaging process used in defining the average flame length $z f$ is important and different techniques have lead to substantial variations in values of $z f$ for the same fire.

The large size of these structures and the speed at which they evolve suggests that they play an important part in fixing the entrainment and heat release in the lower part of the flame.

Elame height measurements. In contrast to momentum dominated flows of regime v, for which the flame length is approximately independent of the fuel flow rate but scales with the diameter of the burner, the buoyancy controlled flame height depends on the heat addition rate as well as the diameter.

Although the appropriate dimensionless parameters which should be used in describing the rlame height in regimes II and III have not been certainly defined, Zukoskj (1975) and Zukoski et al (1981), have found that the parameter Q*, defined above in equation (1) is satisfactory in regime II. Note that in this parameter the properties of the fire which appear are the total heat release rate and the initial diameter. The product ( $\rho_{\infty} \mathrm{Cp}_{\infty} \mathrm{T}_{\infty}$ ) is proportional to the pressure, and hence could be evaluated within the flame or outside in the ambient atmosphere without substantially affecting the value of the parameter. Although $Q$ and $D$ have been varied greatly in buoyant flame experiments, the product $\left(\rho_{\infty} C p_{\infty} T_{\infty}\right)$ has not and thus there is no experimental evidence to support their inclusion in this scaling parameter. For this reason, a number of investigators have used the dimensional parameter $Q /(D)^{5 / 2}$ to correlate their data.

A selected set of data for flame heights obtained from various investigators are shown in Figures 3 and 4. In Figure 3 , the data are eye averaged values and the experimental data from a number of sources, which are shown in this Figure, are in rough agreement for the whole range of $Q^{*}$. However, the scatter is so large that they may hide a more subtle dependence on parameters not used here.

The data for the lower values of $Q$ are shown in Figure 4 . The data shown here are eye averaged values taken from. Wood et al (1971), Alvarez (1984), Kung and Stavrianidis (1985), and Blinov and Khudiakov (1955), and average flame helghts obtained by analysis of video tapes by cetegen et al (1984). The error bars on the cetegen data show the $5 \%$ and $95 \%$ intermittency heights for these flames. 


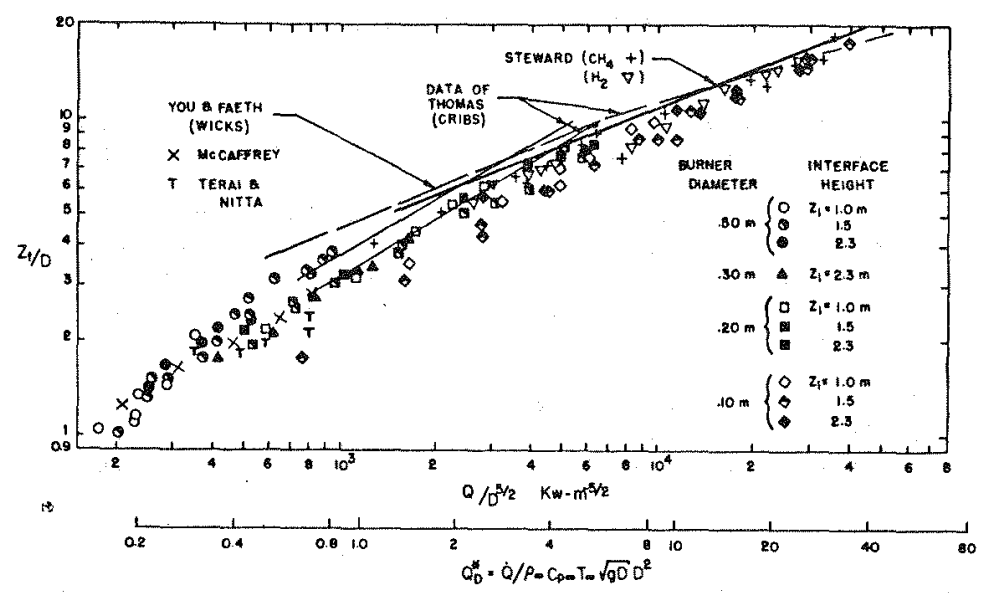

FIGURE 3. Eye-averaged flame length.

The eye averaged data which appear in Figure 3 lie near the top of these bars and hence are some $25 \%$ higher than the average values. Burner diameters for the data reported in Figure 4 range from 0.5 to $23 \mathrm{~m}$. and, despite the earlier correlations of Becker and Liang (1978), our interpretation of the data for the very large gasoline fires of Blinov and Khudiakov agree with other data for regimes II and III in a reasonable manner.

The curves fit to these data delineate regimes I, II, and III, discussed above. For values of $Q^{*}$ between one and several hundred, a reasonable estimate of the average flame height for buoyant plumes is given by

$$
\mathrm{Zf} / \mathrm{D}=3 \cdot 3\left(\mathrm{Q}^{*}\right)^{2 / 5}
$$

The value of the constant can easily be $25 \%$ larger depending on the method used to measure the flame height. Given the definition for Q , the dependence on burner diameter D drops out of the correlation in this regime. This is satisfying, because we expect that the diameter would be unimportant in a buoyant flow when the flame height is large compared with the source diameter.

When $0.1<Q^{*}<1.0$, Cetegen et al (1984) find a correlation of the form,

$\mathrm{Zf} / \mathrm{D}=3 \cdot 3\left(\mathrm{Q}^{*}\right)^{2 / 3}$

However, since this is a transition region, a continuously ohanging slope between 0.4 and 2.0 is probably more reasonable. There is less agreement among various investigators concerning the proper form of this equation than that given for the high $Q$ regime. However, the presence of a transition regime is unambiguous. 


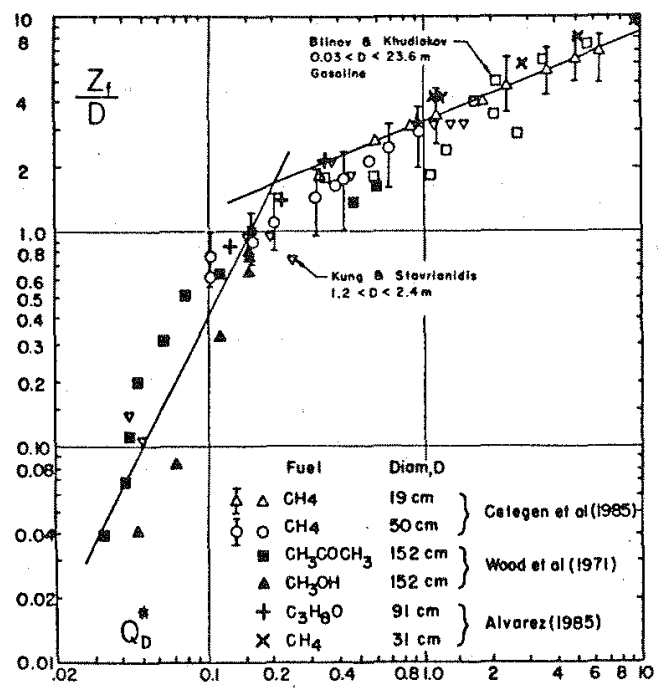

FIGURE 4. Flame lengths for small Q*.

For still smalier values of $Q^{*}$, the data of wood et al (1971) and $\operatorname{cox}$ and chitty (1985) suggest that a correlation of the form,

$\mathrm{Zf} / \mathrm{D}=($ constant $)(\mathrm{Q})^{2}$

may be appropriate for regime I. This correlation reduces to the form

$z f \quad \alpha\left(Q / D^{2}\right)^{2}$

The constant in equation (9) is about 40 for the data of wood et al (1971) and $\mathrm{Kung}$ and Stavrianidis (1985), and about 15 for the data of Cox and Chitty (1985). We cannot explain the difference between these two sets of results. Several processes may be responsible: the square and segmented burner of Cox and Chitty, Q* may not be the appropriate variable in regime I, and finaliy transition to turbulence may oocur differently in the two sets of experiments.

The most well defined correlation presented here is for flames which are more than three source-diameters high and the scatter here is still at least $25 \%$. This scatter is so large that we cannot definitely conclude that the Q* parameter is the appropriate one for this regime. Unfortunately, many accidental fires are in regime I and II for which we have the least reliable data.

Flow parameters. The flame height is difficult to measure because of the large fluctuations in the location of the top of the luminous flame mentioned above. These fluctuations in the visible features of the flame are accompanied by similar fluctuations in temperature and velocity of the gas and they make the determination 
of looal flow properties such as mass, momentum and enthalpy fluxes difficult to make accurately. This difficulty is compounded by experimental problems arising because of the high gas temperature and relatively low gas speeds involved.

Despite these difficulties, a number of experimentors, e.g., MoCaffrey (1979), Kung and Stavrianidis (1985), and Cox and Chitty (1985), have made measurements using thermocouple probes to measure temperature and a variety of pitot-like probes to measure velocity. The influence of large fluctuations and radiation on the thermocouple data were often ignored and the averages of the fluctuating quantities produced by the instrumentation were used without correction. An example of centerline temperature and velocity profiles taken from the data of McCaffrey (1979) is given in Figure 5 for a $60 \mathrm{~kW}$ flame in regime II. The time averaged. values for velocity are small, and those for the temperature are far below the adiabatic flame temperature.

These data cover flames in regimes II and show that velocity profiles change substantially as $Q^{*}$ decreases from 1.0 to 0.1 where as the temperature profiles for these regimes are very similar. Scaling laws for centerline temperature and velocity vary somewhat between these three papers. The general levels of temperatures and velocities are in reasonable agreement among them but there is considerable variation in the velocity data. Kung and stavrianidis (1985) propose the use of an offset, of the type described below, for the origin for the vertical coordinate and Cox and chitty (1985) use a slightly different scaling approach for small values of $Q^{*}$

Entrainment rates. The measurements of velocity and temperature described above are usually of insufficient extent or acouracy to allow estimates to be made of the heat release rates or the mass flux within the flame as a function of height above the burner for flames in the low Q" region.

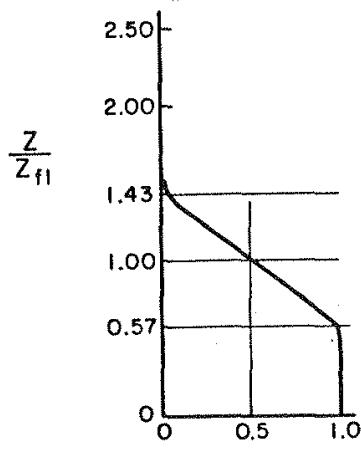

INTERMITTENCY
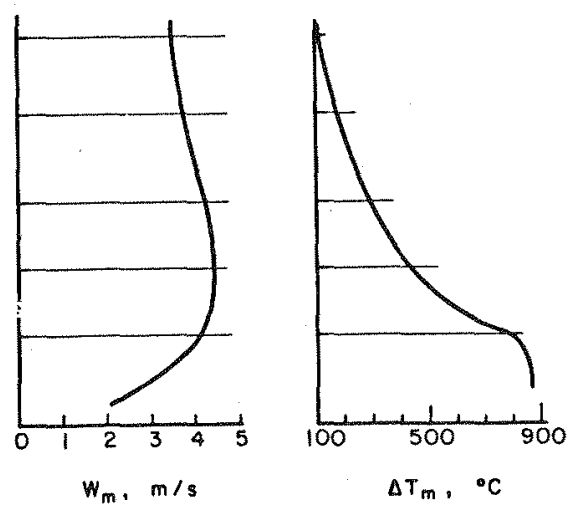

FIGURE 5. Velocity on temperature profiles on centerline of flame. 
Direct measurement of the plume mass flux have been made by several techniques. One, described in zukoski et al (1980), uses a hood to create an interface similar to that expected in the two layer model to trap the plume flow, and a mass balance is performed on the ceiling layer, to measure the plume mass flux. The technique measured the flux into the layer, not the plume flux and there may be some difference between these two. Data obtained with this technique have been obtained for regime II and III flames and the plumes rising above them.

In the lowest part of the flame, the entrainment rate for regime III flames is independent of the fuel flow rate and is roughly proportional to the diameter of the burner. Data from Zukoski et al (1980) and Cetegen et al (1984), and that of Beyler (1984) are in agreement on these results but differ in magnitude by about a factor of two. Some of this spread is certainly due to differences in technique and some to differences in experimental constraints on the fire plumes.

Entrainment in the upper part of flames in regime III was more plume like and did depend on heat release rate and source-diameter. A typical set of data from Cetegen et al (1984) for a 19 cm burner is shown in Figure 6 to illustrate these two regions of entrainment. Note that for small elevations, the entrainment is independent of the heat adition rate but that for larger elevations, the data show a strong dependence on this parameter.

In regime II, entrainment for the entire flame is similar to that for the lower region of flames in regime III and is independent of the heat release rate.

The measurements discussed here are not definitive and more work is required. In particular, the role of the fluctuations in fixing the flux of mass, momentum and enthalpy in the flame should

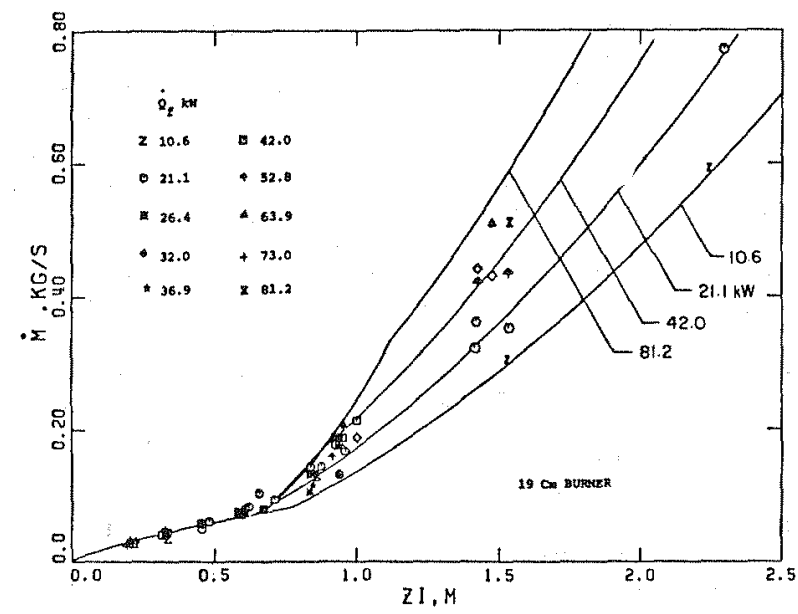

FIGURE 6. Plume mass flux versus height. 
be clarified. Attempts to predict these results from simple models have not been particularly convincing. For example, see cetegen et. al $(1984)$.

Delichatsios and Orloff (1984) have made measurements of entrainment rates in jet diffusion flames using the method suggested by Ricou and Spalding (1961). Values of Froude numbers used in these experiments ranged from 2 to 230 and values of $Q *$, from 230 to 2600. Given the large size of these parameters, these flows are clearly in the transition region between regimes III and $V$ and hence we expect that they were strongly influenced by the initial momentum of the source. Direot comparison of entratnment rates measured in these experiments with those measured with low $Q^{*}$ flames of interest to us here is inappropriate. In addition, the absence in these experiments of the flow pulsations, observed at the base of $10 \mathrm{Q}$ flames, is most probably explained by the very high source Froude numbers used here.

Heat release distribution. Tamanini (1983) has made direct measurements of the vertical distribution of heat release and species concentration in two flames with $Q^{*}$ values of 1.1 and 0.54. Because his technique involves quenching the flame at the measurement plane and the use of a coflowing air stream, we believe that it may introduce a significant distortion of the flow at that elevation and may also suppress the large structures which are characteristic of 5 lames in this regime. Data are presented for two flames which are in the upper part of regime II, a transition regime. The data for the two flames differ substantially and, if accurate, suggest that substantial changes occur in the combustion processes in this regime.

\section{Far Field Plume}

The term far field is used to designate the adiabatic plume region which rises above the flame. Extensive modeling work has been carried out since the $1950^{\prime}$ s following the paper by Morton et al (1950) and an algebraic model is available which allows a description of average values for parameters in the plume. Given a point source of enthalpy in an infinite body of gas at a uniform temperature, it is possible to derive simple algebraic equations which define the entire flow. When we assume that the profiles in temperature difference and velocity are Gausian, the time averaged values of the Gaussian half width of the plume, and the time averaged values for the velocity and temperature difference on the centerline can be predicted with satisfactory accuracy. These results can be put in a variety of forms, e.g. see Morton et al (1950) and Cetegen et al (1984) but the basic results are identical. The validity of the general form of this representation has been verified by a number of authors for the flow in the far field and, at most, there is still some argument over the values of some of the constants which appear in the equations.

However, an adiabatic plume rising above a fire has the top of the fire as its real source and, in order to use the simple formulation described above, we must be able to locate an effective source for the plume which clearly must lie below the top of the flame. 
Given the fluxes of mass, momentum and enthalpy which characterize a distributed source, it is possible to find the elevation for the origin of a point source of enthalpy which produces a flow which is asymptotically identical to that produced by the distributed source. The two flows become identical in the limit of large distance from the source because, in the far field, the influence of the initial momentum and mass fluxes of the distributed source will become vanishingly small compared with the mass and momentum flux in the plume. See the discussions of Morton ( 1958 ) and Kubota (1982). This fictitious source allows us to use the simple algebraic representation for the point source to calculate plume properties in the region above the top of the flame.

To calculate the location of the effective source, we require estimates for the mass, momentum and enthalpy fluxes at the top of the flame. Kubota (1982) has carried out oalculations of this type in the following manner. The mass flux was measured at the top of a flame with a known heat release rate, see cetegen et al (1984). An estimate for the maximum velocity was obtained from a correlation of McCaffrey (1979) and was combined with the mass flux measurement and a Gaussian model for the flow to calculate the momentum flux. These data were then used with a numerical model of Kubota (1982) to calculate the elevation of the source for the plume.

Experimental schemes for locating the height of the effective source have been proposed, by Heskestad (1983), Cetegen et al (1984), and by Kung and Stavrianidis (1985), and the method suggested by Cetegen et al is illustrated in Figure 7 . Here, experimental values for the offset $z_{0}$, divided by the source diameter D, are shown as a function of the ratio of flame height to burner diameter, Zf/D. The offset is taken as the distance between the surface of the burner and the fictitious source, and is defined to be positive when the source lies beneath the burner. Note that the offset is small when $Z f / D$ is small, and is negative and not more than 2 diameters even for $\mathrm{Zf} / \mathrm{D}>8$. Data from Heskestad (1983) and Kung (1984) obtained with large fires are shown here and agree satisfactorily with the data obtained with the smaller fires.

Values for the offset calculated by the method proposed by Kubota are shown here by the two points with error bars located close to the lower curve. They are in good agreement with the experimental values shown here and continue to agree up to values for $2 f / D$ of 20. The error bars show the effects of changing the estimated velocity by a factor of two and they indicate that the results are not very sensitive to errors in velocity.

One of the interesting features of these plumes is that the entrainment rate of air measured at the top of the flame is that which would be predicted for a well developed buoyant plume. Thus, the transition between the flame and far field regions is very rapid. In addition, the measured entrainment rates are those predicted from a Boussinesq analysis even though the ratio of plume and air temperatures at this elevation is large.

Another of the interesting features of these fire plumes is that at the top of the visible flame the flow of air entrained into the fire plume is about 14 times more air than would be needed to react with the fuel flow from the source. This large excess is an important feature of the diffusion flames we are describing here 


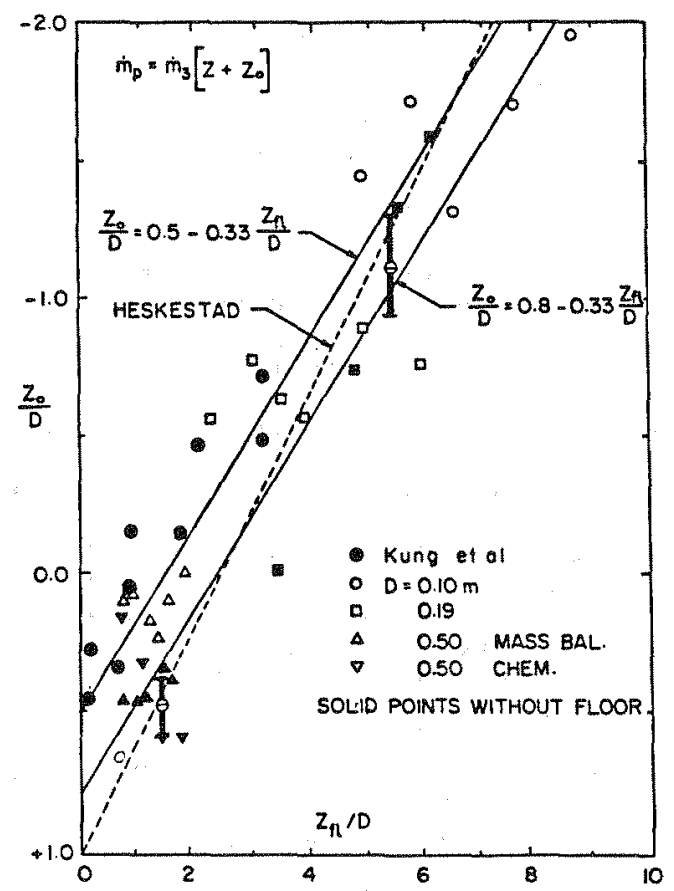

FIGURE 7. Offsets for fleld plume.

because it means that a flame which penetrates a large distance into a ceiling layer where the oxygen concentration is very low may still entrain sufficient oxygen from the lower and unvitiated layer to allow complete combustion to occur.

In summary, the height of the flame, $\mathrm{zf}$, can be predicted from a knowledge of the heat release rate and burner diameter. Then this value can be used to predict the elevation of the effective source which in turn can be used to predict the entrainment rate and other properties of the adiabatic plume which rises above the fire. These predictions are applicable for the region above the visible flame and can be used at the top of the flame. Thus, many of the properties of the plume produced by a large diffusion flame, rising above the simple sources described here, can be predicted with confidence.

Data for entrainment into the flame itself are less reliable and more data of this type are needed. In the low $Q$ regimes, the data are least reliable in the range $Z f / D<3$ and this is just the region of most interest in accidental fires.

Finally it is clear from the discussion of the various flow regimes given here that the properties of the flow depend strongly 
on the flow regime. Thus when we compare results obtained from different experiments, and in partioular when we compare small scale laboratory experiments with large scale accidental fires, we must be certain that the flames being considered are in the same flow regime and that we are observing similar parts of the flame.

\section{Plume Interactions}

Limitations of space make it impossible to deal with a number of interactions between a buoyant fire plume and it's environment. Several important interactions for which information is available are briefly mentioned here. In each case, we consider the interaction with the fire plume which includes both the flame region and the adiabatic plume above it.

Wall. When a fuel bed is in close contact with a wall or is placed in a corner, the plume rising above the bed may attach to the wall and the wall may then strongly influence the entrainment into the plume. A simple reflection principal, see zukoski et al, (1981), suggests that the entrained air flow is reduced and the gas temperature is increased. Hasemi and Tolunaga (1984) have presented a review of the subject and new experimental work which shows that this choice of the simple approach is not completely correct.

Ceiling. The flow produced by a fire plume impinging on a ceiling determines the convective heat transfer rates and the initial properties of the ceiling jet formed by the plume flow. This flow has been the subject of a number of papers such as Alpert (1971), Zukoski and Kubota (1975), You and Faeth (1979), Cooper (1982) and Sargent (1983) and the flow produced by this interaction is discussed below in section $I V$.

Interface The impingement of a buoyant plume on an interface separating gas layers with large density differences has been discussed by Baines (1971), Cooper (1982), and Zukoski and Mak (1985). The probiem here concerns whether or not the plume will penetrate the interface and if it does penetrate, how much of the plume material flows into the interface. Zukoski and Mak (1985) suggest that when an average plume density, based on the mass-fluxaveraged plume temperature, is less than the density in the ceiling layer, the plume will penetrate cleanly into the ceiling layer and rise to the ceiling. No plume gas is left at the interface. When this average plume density is less than that in the upper layer, penetration will. still occur but the mixed material produced by the interaction will return to the original interface to produce a third layer.

Cross flowe Finally, the interaction of the fire plume with cross currents and random disturbances is an important feature of room fires which requires further clarification.

\section{FLOW THROUGH OPENINGS}

The flow of gases through openings, such as windows and doors, which are typical of those found in buildings, is discussed in this section and we will not deal with flows through ducts such as those used in air conditioning systems in which mixing between hot and 
cold streams may be a dominant feature. Three examples of the flows which may be present during the development of a fire are

illustrated in the sketches of Figure 8. They include flow through a doorway and window in a vertical wall, and flows though an orifice in a horizontal surface with a smoke layer below the opening.

The doorway and window flows shown here are the standard flows which are addressed successfully in most models. However, in some circumstances, the flow of fresh air from the second room into the lower layer of the fire room can cause entrainment of hot products into the lower layer in the fire room and thus can lead to substantial contamination of the air in this layer. This mixing process is illustrated here for the window flow, but can also occur in doorway flows and in general cannot yet be described adequately.

Finally consider the situation shown in sketch (c) in which smoke generated on the first floor of a house flows through an opening in the ceiling. We assume that the house is well ventilated so that the pressure difference across the oeiling and at the opening is fixed by the depth of the hot smoke. As long as the depth of the hot gas layer is larger than the diameter of the hole, see the right hand side of sketch $c$, the flow will be similar to that through an orifice. When the layer is thinner, see left hand side of sketch c, the flow resembles that of a fluid across a broad crested weir and smoke may not fill the whole opening.

The plumes formed above or below the orifice for the configurations described above all resemble conventional turbulent, buoyant plumes. However, some procedure, such as that discussed above for the adiabatic plume rising above a flame, must be used to establish an effective elevation for the source of the plume.
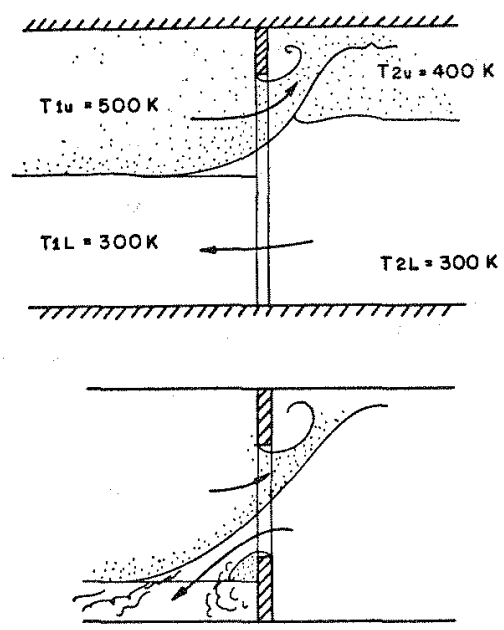

(A)

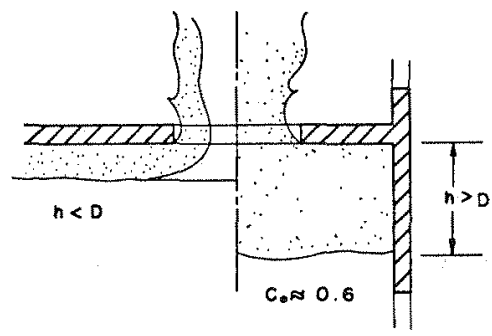

FIGURE 8. Flow through openings. 
The calculation of the rate of flow of smoke through openings In vertical or horizontal surfaces is another area where models are avaliable which are a step beyond simple dimensionless analysis. The information developed in studies of flow of gases or liquids through orifices, where buoyancy plays no part, and the flow of liquids across weirs, for which buoyancy is paramount, has been of great help here.

The first model for flows through a vertical surface such as a wall, which was brought to the attention of the fire research community, was developed by Kawagoe (1958) for the limiting case of a flow through an opening in a vertical surface which separated a hot gas inside of a room from ambient air on the outside of the opening. His model has been modified and extended over the past ten years by a number of authors, (e.g., Prahl and Emmons (1975), Zukoski (1975), Quintiere and DenBraven (1978) and Stechler et al (1980) to name a few) and present models are applioable, with accuracies at the 10 to $20 \%$ level, to the wide range of conditions which can exist when the two layer model is assumed to be applicable.

To illustrate the type of model used which has developed, consider that proposed by zukoski (1975). The basic idea used in this model is that the flow through any opening can be modeled as an integral, over the area of the opening, of the flow through infinitesimal orifices each of which acts as an ideal 1 solated orifice in a wall. The velocity of the gas at the plane of the orifice, the direction of the flow, and the mass flux can be calculated by the conventional orifice equations given the local pressure difference across the orifice and properties of the gases on either side of the opening.

Even when density gradients in the vertical direction are allowed on either side of the surface, this model allows the flow to be calculated when the distribution of densities and a pressure difference at one elevation are specified. This model is best suited for the description of the flow through small openings in large walls and becomes less reasonable as the area of the opening approaches the area of the wall. However, even this type of flow can probably be treated by a modification of the analysis which has been developed to describe flow over a weir.

The models used to calculate flows through orifices typically contain a constant called the flow coefficient which is the ratio of the measured to theoretical flow rate and the coefficient is used to take into account a number of effects such as flow separation from sharp corners or viscous effects which are not covered by the theoretical model. The flow coefficients for flow through rectangular doorways and windows which are used in various fire models have values which range from 0.6 to 0.8 and a value of 0.7 seems a reasonable compromise. The use of a single constant ignores the effects on the flow of opening geometry, Reynolds number, radii of curvature of the lip of the opening, and approach stream velocity. These effects are usualiy in the 5 to $10 \%$ range. The large Reynolds number effects reported by Prahl and Emmons (1975) are incorrect and result from surface tension forces acting on the two immiscible fluids used in their tests. 
For the flow through an opening in a vertical surface, the difference in densities on either side of the opening enters the calculation of the pressure difference across the opening but has no other effect even when pressure differences are small. However, if we consider the flow of gas through a horizontal surface, it is clear that some flow will occur even if the pressure difference across the wall is zero when the more dense fluid lies above the less dense. Thus, when the pressure drop across the surface becomes too small, the effects of buoyancy forces on the fluid near the opening will have an effect. We expect that the pertinent parameter here is the ratio of a gravitational force based on the opening diameter $D$ and the pressure difference $\Delta \mathrm{P}$ :

$\Delta \rho \mathrm{g} D / \Delta \mathrm{P}$

Here, $\Delta \rho$ is the density difference of the two fluids, and $g$ the acceleration of gravity. Recent experiments suggest that when this ratio, becomes larger than 0.5 , the flow coefficient will be influenced by buoyancy effects.

Observations of the flow, made in on-going salt-water/water experimental studies, for this zero pressure-difference case show that an unsteady flow develops in which puffs of fluid from either side of the ceiling flow into the other. Flow rates are not negligible, but a quantitative prediction for the magnitude of the flow in conditions similar to those encountered in building fires is not yet available.

Finaliy, when the depth of a layer of hot gas lying beneath an opening is smaller than the opening diameter, the flow through the opening will be similar to that shown on the left hand side of Figure $8 \mathrm{c}$, with the additional assumption that the pressure difference across the celiting of the first floor is imposed by the depth of the hot gas itself. For this condition, we expect that the flow coefficient will be as low as 0.4 . However, when the thickness of the hot gas layer exceeds the diameter of the hole, see right hand side of Figure $8 \mathrm{c}$, the flow will again be similar to that through an orifice and the coefficient will rise to values around 0.6 .

Based on the information avalable for horizontal and vertical surfaces, it is reasonable to expect that the flow through surfaces with arbitrary orientations with respect to the gravitational vector can be described by the same orifice-like equations as were found to be useful for the two orientations described above. However, we would also expect that this approach will fail when the ratio of buoyancy force per unit area based on the opening scale approaches the imposed pressure difference across the opening.

\section{FLOW IN CEILING LAYER}

One of the great simplifications resulting from the use of the two layer model is that the details of the flow within the layers can be ignored. However, a rudimentary description of flow within the layer is required to allow the calculation of convective heat transfer from the gas to the walls of the room. In addition, strongly stratified layers have been observed recently in several full scale fire experiments and in similar smaller scale experiments 
at calteoh. The temperature gradients in the ceiling layer observed in these experiments were large and in some cases were almost constant across the height of the layer. When this stratification is present, we clearly need a much better model to describe the flow within the upper layer.

These experimental results force us to consider the factors Which lead to the development of the poorly mixed layers. our primary aim here is to make qualitative arguments concerning the developmeni of stratification and to present some preliminary results of a model being developed to describe this prooess. In the following paragraphs, we first consider the gravity current produced when the plume first reaches the celling and then the development of recirculating currents within the upper layer which have a strong influence on stratification in the layer.

\section{Ceiling Jets}

In the initial stages of a fire within an enclosure, the plume of hot gas produced by the fire rises due to buoyancy forces and impinges on the celiling to form a layer of hot gas, called the celling jet. This fluid spreads out from the impingement point to form a thin layer which spreads to reach the walls with a relatively constant thickness. Later, this layer grows in depth to form the ceiling layer. A similar process occurs in a room adjacent to the fire room where the source is a plume from a doorway.

This process is illustrated in Figure 9 for a two-dimensional flow into a hallway. Near the plume impingement point, the flow entrains cooler fluid, but within a short distance buoyancy forces prevent further entrainment and the plume moves across the hall ceiling with constant mass flux and a constant thickness. The velocity of the front and the temperature in the gas near the head of the current decreases with distance from the source due to heat Ios $\mathrm{s}$
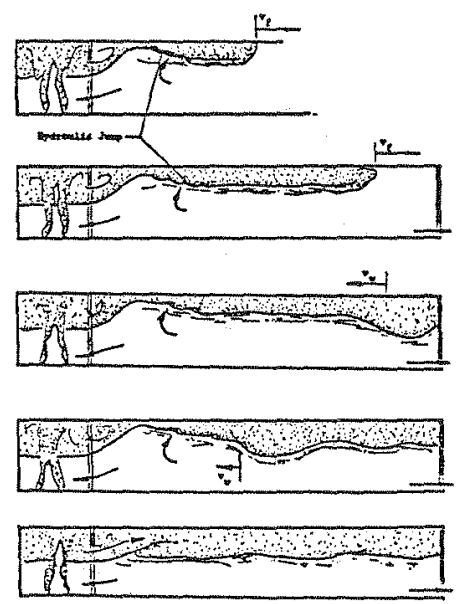

FIGURE 9. Ceiling jet flow. 
to the wall and wall shear. The current reaches the far wall, is reflected and returns to flood the entrainment region near the plume. When the hall length is more than three or four room-heights long, the temperature in the reflected flow is typlcally much less than that at the source because of convective heat transfer and this difference remains large until the ceiling surface temperature rises to a value comparable to the initial plume temperature. Flows of this type have been described in a review by Zukoski and kubota $(1984)$.

We are developing a simple integral model to analyze the plume and ceiling jet system. which takes into account shear forces and heat transfer at the wall, and entrainment from the gas beneath the current. An important parameter which appears in this analysis is the Richardson number for the jet, which is defined as the ratio of the gravitational forces acting over a height corresponding to the thickness of the jet, $\delta$, to the momentum flux in the layer or

\section{$\mathrm{Ri}=\left(\Delta \rho_{\mathrm{B}} \delta\right) /\left(\rho_{\mathrm{c}} \mathrm{Vc}^{2}\right)$}

Here, $\Delta \rho$ is the difference in density between the fluid adjacent to the jet and the jet fluid, g is the acceleration of gravity, and $\rho_{c}$ and Vo are the density and characteristic velooity in the ceiling jet. When the Richardson number is large, gravitational effects will be dominant and entrainment into the jet will be supressed; when it is small, momentum effects will be dominant and entrainment will be important.

The integral model shows that the Richardson number of the flow at the start of the ceiling jet is independent of both the height of of the fire plume and the heat release rate of the fire, and that the plume height is the proper saling length for the initial thickness of the ceiling jet.

The analysis shows that near the plume impingement point where the ceiling jet is formed, the Richardson number in the jet is less than one. However, as the jet entrains fluid, the Richardson number grows with the square of the distance from the impingement point. Thus, within a distance which is comparable to the plume height, it typically reaches values larger than one. In this high Richardson number regime, no mixing or entralnment occurs between the fluid in the jet and the adjacent fluid and the jet propagates across the ceiling with constant mass flux.

The propagation velocities for ideal inviscid, adiabatic jets for which the layer thickness, $\delta$, is small compared with the room height are proportional to $\sqrt{\mathrm{g} / \mathrm{F}}$ and the proportionality constant is between 1 and 1.40 . Here, $g^{\prime}$ is $g\left[\left(p_{2}-p_{c}\right) / \rho_{2}\right]$, the reduced acceleration of gravity based on the difference between the densities of the current, $\rho_{c}$ and that in the gas below the current, $\rho_{2}$. Heat transfer effects enter primarily through a reduction in this density difference ratio.

Velocities for ceiling jets produced by large fires are typicaliy in the range of 0.2 to $2 \mathrm{~m} / \mathrm{s}$ near the start of the jet. Consequently in a room with a lateral scale of a few meters, fluid in the jet will reach the side walls within a few seconds and the complexities of this flow can be ignored in describing the development of the layer. However, when the room has a lateral 
dimension which is very large compared with its height, the time scale for this process can become important.

Later on in the development of the fire, the effects of the heat transfer from the ceiling jet can also have a large effect on the flow within the upper layer. These will be discussed in the following section.

\section{Stratification}

The degree of stratification in the ceiling layer depends in detail on the flow within the layer as well as the action of the fire or doorway plumes, flows into and out of the layer at openings and heat losses to the ceiling and walls by convection and radiation. A number of processes can be identified as acting to increase or decrease the stratification of the gas in the layer and several of these are discussed in the following paragraphs with the aid of the sketches presented in Figures 1,10 and 11 .

Given the picture of the development of the fire in a compartment given in the introduction, it is clear that the processes of fire growth and heat transfer tend to produce a stratified layer and the real question is: Why do we get a wellmixed layer at all?

A number of processes act to reduce the degree of stratification. One of the most important of these is the entrainment, into the plume and the ceiling jet, of gas from the ceiling layer which produces a recirculation of gas within the ceiling layer. Since gas is entrained from all levels of the layer and mixed with the flow in the plume and ceiling jet, this entrainment process will act to reduce stratification and it is the primary process which may produce a well mixed ceiling layer.

A second factor which reduces stratification is the flow of gas out of the ceiling layer through a doorway, window, or other opening. For example, when this flow is withdrawn from the bottom of the layer, as it would be for a doorway with a soffit, high density gas near the interface will be the first to move down to reach the door soffit and hence will be the first to be removed.

A third factor, the flow path produced by the impinging plume and the resulting ceiling jet, is of major importance and can act either to increase or decrease stratification. The flow in the ceiling jet moves along the ceiling until it impinges on the side walls, and at that point it must turn downward. If the gas in the ceiling jet has sufficient momentum and a small enough buoyancy, with respect to the ceiling layer gas, it may flow down the side walls to reach the interface between the ceiling and floor layers before buoyancy forces overoome its downward momentum. This overshooting flow will cause strong mixing within the layer. However, if the momentum in the jet is small compared to gravitational forces, the ceiling jet will turn back over itself and flow back toward the plume. Less mixing will occur for this flow than for the previous one.

The parameter which controls the motion of the plume at the side wall is the Richardson number for the ceiling jet based on the 


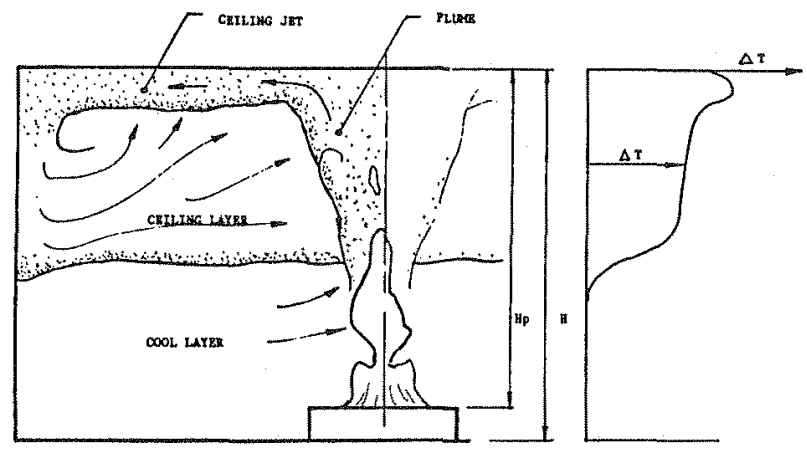

FIGURE 10. Ceiling layer flow, well mixed.
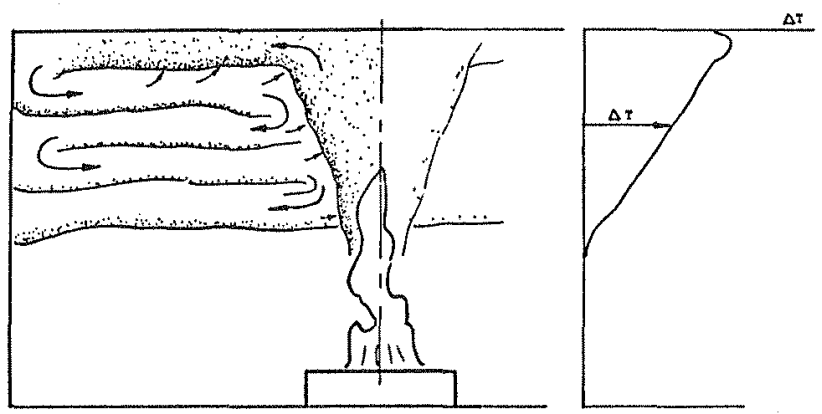

FIGURE 11. Ceiling layer flow, poorly mixed.

density in the jet and in the adjacent ceiling layer. When the Richardson number is still small, the jet will turn through 90 degrees at the corner and will have sufficient momentum to move down into the celling layer, a distance corresponding to many ceiling jet thicknesses. This is the flow pattern shown in the sketch in Figure 10. For low Richardson number flows, both the ceiling jet and the fire plume entrain fluid from the whole hot layer and a rapid recirculation results from the vortical motion. This flow pattern and the entrainment into the plume and ceiling jet produces a well mixed ceiling layer with weak density gradients except near the interface with the cool layer. In this example, heat transfer can reduce the gas temperature, but the effects of this process are spread throughout the whole layer.

If the Richardson number of the celling jet is large when the gas impinges on the side wall, the fluid in the jet still must turn but it no longer has the momentum required to penetrate any appreciable distance downward. Buoyancy forces act to force the flow to turn back toward the plume and move under the outflowing gas in the ceiling jet. This type of flow pattern is shown in sketch of Figure 11 .

Here, the flow forms a stream with a sinuous path and material from this stream is entrained in the plume, but little is entrained 
into the ceiling jet because no entrainment is present in the high Richardson number part of that flow. Thus in this case, only a small part of the material in the recirculating flow is entrained into either flow as it approaches the interface to form the lower part of the ceiling layer. Because fluid is not entrained into the plume or ceiling jet, it undergoes little mixing and will retain its original temperature and composition. In a fire situation in which the material delivered to the ceiling by the fire plume experiences an increase in temperature, due to the growth of the fire and a decrease with time of convective heat transfer, this process will create a strongly stratified layer.

Thus, the pattern of the flow rather than the total heat transfer or the rate of recirculation is important here in fixing the stratification in the layer.

The two examples discussed above are limiting cases which are observed in room fires and the problem, not yet resolved to our satisfaction, is to predict at what radius the transition between them wili occur in rooms with a geometry of interest to us.

Estimates based on an idealized model for flow in the ceiling jet show that the Richardson number will be less than one at the origin of the ceiling jet and that it will grow roughIy as the square of the distance from the plume. Thus we expect that the transition between the overturning flow of the well mixed case and the weakly mixed case will depend strongly on the geometry of the room and more weakly on other characteristics of the system. The idealized integral model indicates that the transition between low and high Richardson number behavior will occur at a radius, measured from the plume axis, of 1 or 2 plume helghts. The transition point for a particular situation will depend on the values selected for the coefflcients used to describe convective heat transfer, wall shear and entrainment rates, and hence is at least weakly dependent on the Reynolds number of the jet.

A number of small scale experiments suggest that this result is correct. For example, experiments carried out by Baines and Turner, (1969), and later by Tangren et al, (1978) with the salt-water/water modeling technique, suggest that the correct geometrical parameter to use in deciding which of these two flow patterns are to be expected is the aspect ratio for the room. Based on their experiments, Baines and Turner (1969), propose that the transition occurs when the aspect ratio, the ratio of lateral room dimension to plume height, is between one and two.

These experiments were carried out for a geometry in which the fire is located on the floor and at the center of a square room, and this configuration was also used in carrying out the integral model whose pesults are described above. If the plume is not located at floor level in the center of the room, the correct scale lengths are the mean distance from the looation of the fire to the walls and the height of the plume.

This transition criteria is clearly a very crude one and a more refined definition would depend on other parameters of the system such as the Reynolds number of the flow in the ceiling jet and even the thermal properties of the celifing material which can affect the influence of the heat transfer process. The influence of these parameters is now being investigated. 
The flow through a doorway or other opening in a vertical wall which has a soffit substantialiy below the level of the ceiling of the adjacent room will produce a plume-like flow and a ceiling jet, see Figure 9. The major difference between this doorway plume and the fire plume is that the doorway plume will usually be much shorter than the fire plume and hence will produce substantially smaller rates of entrainment and recirculation. In addition, the plume height will usually be much smaller than the room height and consequently the transition between low and high Richardson flows will occur much closer to the plume impact point. Thus, for many reasonable room and soffit geometries, the flow in the adjacent space will be in the high Richardson number regime for which we expect strong stratification. Based on this discussion, we should expect that strong stratification will be more common in spaces adjacent to the room of fire origin than in the room containing the fire.

The material discussed above suggests that strong stratification may exist in many situations of interest to us. Stratification will affect energy transport processes by convection and radiation which depend on temperature differences, and mass transport through openings which depends on the density distribution in both layers.

The magnitude of these effects is time dependent: early in the history of the fire, stratification will often be important; later if mixing increases and outflow processes become important, the effects of stratification may be negligible.

However, when stratification is large, some modification must be developed for the two layer model to allow an accurate description of transport processes. As interest shifts to modeling flows in rooms adjacent to or far from the room in which the fire originates, the need for a more detailed description of flow within the ceiling layer will become more urgent.

\section{CONCLUDING REMARKS}

The discussion given above shows that the properties of the flows produced by large buoyancy controlled diffusion flames depend strongly on the flow regime for the flame. For example, data for flames in regimes II and III show that flame length dependence on $Q^{*}$, and entrainment rates and, to a lesser extent velocity and temperature on the flame centerline, change substantialiy between these regimes. Only flame length data are available for regime I flames, and they show again a large change in the dependence on $Q$.

The dimensionless parameter Q , used here to correlate the flame height data and to define these regimes for the three buoyancy controlled flame regimes appears to be a satisfactory parameter for regines II and III. However, the data are too scattered to allow a very precise test of its validity and its use in regime I is suspect although very little data are avallable for this regime.

For flows with larger Froude numbers, substantial changes occur as the transition from buoyancy controlled to momentum controlled flames occurs. The correct transition parameter here appears to be a Eroude number, and not $Q^{*}$, and experimental results obtained with 
a wide range of fuel types would be useful here in defining the transition process more certainly.

The recognition that flow properties change substantially with flow regime is critical for those modeling diffusion flame phenomena.

A transition of a different type can occur in the ceiling layers of room fires - the transition between a well-mixed and a stratified ceiling layer. The present work suggests that this transition is most sensitive to room geometry and starts to occur when the ratio of the horizontal scale of the room to the plume height is greater than 2. Because plume heights in rooms adjacent to the fire room are often smaller than that for the fire plume or are entirely absent, we expect that stratification will be more prevalant in the adjoining rooms. Should this suggestion prove correct, some modification to the usual two-layer modeling approach must be developed to account for the influences of stratification on the transport of energy and mass.

\section{REFERENCES}

Albert, R. L.: "Fire Induced Turbulent Ceiling-Jet," FMRC Serial No. 19722-2, Factory Mutual Research Corp., Norwood, MA, 1971.

Alvarez, N. J.: Personal communication, 1985.

Baines, W. D. and Turner, J. J.: "Turbulent buoyant convection from a source in a confined region," J. Fluid Mech., 37, pp. 51-80. 1969.

Baines, W. D.: "Entrainment by a plume or jet at a density interface," J. Eluid Mech, vol. 68, part 2, pp. 309-320, printed in Great Britain, 1975 .

Becker, H. A. and Liang, D.: "Visible Length of Vertical Free Turbulent Diffusion Flames," Combustion and Elame, 32, pp. 115137,1978 .

Becker, H. A. and Yamazaki, S.: "Entrainment, Momentum Flux and Temperature in Vertical Free Turbulent Diffusion Flames," Combustion and Elame. 33, 1978 .

Blinov, V. I. and Khudiakov, G. N.: Dok1. Akad. Nakㅗ SSSR, 113, 1094. Reviewed by Hottel1, H. C. (1959) Eire Res. Abstr Rey., 1 , p. $41,1957$.

Cannon, J. B. and Zukoski, E. E.: NTurbulent Mixing in Vertical Shafts Under Conditions Applicable to Fires in High Rise Buildings," Technical Report No. 1, to the National Science Foundation, California Institute of Teohnology, Pasadena, California, 1975 .

Cetegen, B. M., Zukoski, E. E., and Kubota, T.: "Entrainment in the Near and Far Field of Fire Plumes", Combustion Science and Technology, Vol. 39, pp. 305-331, 1984 .

Cooper, Leonard Y.: "Convective Heat Transfer to Ceilings Above Enclosure Fires," 19 th Symposium (Int.) on Comb./The Comb. 
Institute, pp.933-939, 1982 .

Cox, G. and Chitty, R.: "Some Source-Dependent Effects of Unbounded Fires," Combustion and Flame, Vol. 60, pp. 219-232, 1985 .

Delichatsios and Orloff: "Entrainment Measurements in Turbulent Buoyant Jet Flames and Implications for Modeling," Factory Mutual Report FMRC J.I. OKOJ2.BU, 1984.

Emmons, Howard: "Prediction of Fires in Buildings," 10th Symposium (Int.) on Comb./The Comb. Institute, pp. 1101-1111, 1978 .

Hasegawa, H.K., et al: "Fire Protection Researoh for DOE Facilities: FY 83 Year-End Report," UCRL-53179-83, 1984 .

Hasemi, Y., and Tokunaga, T.: "Some Experimental Aspects of Turbulent Diffusion Flames and Buoyant Plumes from Fire Sources Against a Wall and in a Corner of Walls, "Combustion soience and Technology, 40, 0010-2202/84/4004-0001, pp. 1-17, 1984 .

Heskestad, G.: Fire Safety Journal, 5, p. $109,1983$.

Kawagoe, K.: "Fire Behavior in Room Fires," Bldg. Researoh Institute, Tokyo, Japan, Report Number $27,1958$.

Kubota, T.: "Tubulent Buoyant Plume in a Stratified Media," Report prepared for The Center for Fire Research, National Bureau of Standards, Jet Propulsion Center Report, California Institute of Technology, 1977 .

Kung, H., and Stavrianidis, P.: "Buoynat PIumes of Large-Scale Pool Fires," 19th Symposium (Int.) on Comb./The Comb. Institute, pp. $905-912,1982$.

MeCaffrey, B. J.: nPurely Buoyant Diffusion Flames: Some Experimental Results," NBSIR $79-1910$, Nat. Bur. Stand., Washington D.C., 1979 .

Morton, B. R., Taylor, G. I., and Turner, J. S.: Proc. Royal Soc., A. $234, \mathrm{p} .1,1950$.

Morton, B. R.: "Forced Plumes," Je Eluid Mechanies, 5, pp. 151-163, 1958.

Prahl, J., and Emmons, H. W.: "Fire Induced Flow Through an Opening," Combustion and Elame, 25, pp. 369-385., 1975 .

Quintiere, J. G., and DenBraven, K.: "Some Theoretical Aspects of Fire Induced Flows Through Doorways in a Room-Corridor Scale Mode1," NBSIR 78-1512, National Bureau of Standards, Washington, D.C., 1978 .

Quintiere, J.G.: "A Perspective on Compartment Fire Growth," Combustion Sctence and Technology, 39, $0010-2202 / 84 / 3906-0011$, pp. 11-54, 1984 . 
Railston, W.: "The Temperature Decay Law of a Naturaliy Convected Air stream," Proc. Phys. Soc, 67B, pp. 42-51, 1954.

Ricou, F. P., and Spalding, B. P.: "Measurements of Entrainment by Axisymmetric Turbulent Jets," J. Eluid Mechanics, p. 11, 1961.

Rockett, John A.: "Fire Induced Gas Flow in an Enclosure," Combustion Science and Technology, Vol. 12, pp. 165-175, 1975.

Sargent, W. S.: "Natural convection flows and associated heat transfer processes in room fires," Ph.D. Thesis, California Institute of Technology, 1983.

Steckler, K. D., Quintiere, J. G., and Rinkinen, W. J.: "Flow Induced by Fire in a Compartment," 19th Symp. (Int.) on Comb., The Comb. Inst., p. 913-920, 1982.

Steward, F. R.: Combust. Sci Technol., 2, p. 73, 1954.

Tamanini, F.: "Direct Measurements of Longitudinal Variation of Burning Rate and Produot Yield in Turbulent Diffusion Flames," Combustion and Elame, v. 51, pp. 231-243.

Tangren, E. H., Sargent, W. S., and Zukoski, E. E.: "Hydraulic and numerical modeling of room fires, $n$ Jet Propulsion center Report, California Institute of Technology, 1978.

Thomas, P. H., Baldwin, R., and Heselden, A.J.M.: "Buoyant Diffusion Flames: Some Measurements of Air Entrainment, Heat Transfer, and Flame Merging," Tenth Symposium (International) on Combustion, The Combustion Institute, pp. 983-996, 1965.

Wood, B. D., Blackshear, P. H., and Eckert, E. R. G.: Combustion Science and Technology, 4, p. 113, 1971 .

You, H. Z. and Faeth, G. M.: "Ceiling Heat Transfer During Fire Plume and Fire Impingement," Fire and Materials, 3, p. 140, 1979.

Zsak, T. and Zukoski, E. E.: "Review of Flame Height Data," Report for the Center for Fire Research, National Bureau of Standards, Jet Propulsion Center keport, California Institute of Technology, 1985 .

Zukoski, E. E.: "Convective Flows Associated with Room Fires," Semi-annual Progress Report for 1975 to the National Science Foundation, Grant No. GI $31892 \times 1$, California. Institute of Technology, Pasadena, California, 1975.

Zukoski, E. E., and Kubota, T.: "An Experimental Investigation of the Heat Transfer from a Buoyant Gas Plume to a Horizontal Ceiling, Part 2: Effects of a ceiling layer," NBS-GCR-77-98, Nat. Bur. Stand., Washington, D.C., 1975.

Zukoski, E. E.: "Development of a Stratified Ceiling Layer in the Early Stages of a Closed -room Fire," J. of Fire Materials, 2 , p. 54,1978 . 
Zukoski, E. E., Kubota, Toshi, and Cetegen, Baki,: "Entrainment in Fire Plumes," Fire Safety Journal, 3, pp. 107-121, 1980-81.

Zukoski, E. E., and Kubota, T.: "Two-Layer Modeling of Smoke Movement in Building Fires," J. Fire and Materials, 4, p. 17, 1980 .

Zukoski, E. E. and Kubota, T.: Final Report to the Center for Fire Research, National Bureau of Standards, Jet Propulsion Center Report, California Institute of Technology, 1984.

Zukoski, E. E.,: "Algebraic Models for Jets and Plumes," Report for the Gas Research Institute, Jet Propulsion Center Report, California Institute of Technology, 1984.

Zukoski, E. E.,: "Smoke Movement and Mixing in Two Layer Fire Models," paper presentation at the 8 th U.S. - Japan Panel on Fire Research and Safety, 1985 .

\section{SYMBOLS}

\begin{tabular}{|c|c|}
\hline $\mathrm{p}$ & Specific heat at constant pressure \\
\hline D & Diameter of fire source \\
\hline Fro & Froude number, Wo / $B D$ \\
\hline $\mathrm{g}$ & Acceleration of gravity \\
\hline$g^{\prime}$ & Reduced acceleration of gravity, such as $g(0-0) / 0$ \\
\hline $\begin{array}{l}\text { hf } \\
\dot{m}\end{array}$ & $\begin{array}{l}\text { Heating value of fuel, } J / \mathrm{kG} \\
\text { Mass flux in plume }\end{array}$ \\
\hline$\Delta p$ & Static pressure difference across an opening in a surface \\
\hline$Q^{*}$ & $\begin{array}{l}\text { Heat release rate of fire } \\
\text { Dimensionless parameter, } Q /(0 C D T-/ g D D)\end{array}$ \\
\hline $\operatorname{Re}$ & $\begin{array}{l}\text { Dimensionless parameter, Q/(O CP } T-/ g D D) \\
\text { Reynolds number }\end{array}$ \\
\hline $\mathrm{T}$ & Temperature \\
\hline $\mathrm{Tp}$ & Mass-flux averaged plume temperature, ( $T$ \\
\hline $\mathrm{v}$ & Horizontal velocity \\
\hline Wo & Initial source velocity \\
\hline $\mathbf{z}$ & Vertical coordinate \\
\hline $\mathrm{Zf}$ & Height of top of flame \\
\hline$z t$ & Elevation for transition \\
\hline$\delta$ & Thickness of ceiling layer \\
\hline$\rho$ & Density \\
\hline & Kinematic visc \\
\hline
\end{tabular}

subscripts:

$\begin{array}{llll}\circ & \text { Source value } & \text { c } & \text { Ceiling jet property } \\ \infty & \text { Ambient gas property } & \text { a } & \text { Ceiling layer property } \\ \text { f } & \text { Fuel property } & & \end{array}$

